\title{
Early Intervention to Support Parenting during Pregnancy: Improving Parent-Child Interactions
}

\section{Mami Sonobe $^{1^{*}}$, Masami Usui ${ }^{2}$ and Taiko Hirose ${ }^{3}$}

${ }^{1}$ Department of Nursing Sciences, Graduate School of Human Health Sciences, Tokyo Metropolitan University, 7-2-10 Higashiogu, Arakawa-ku, Tokyo 116-8551, Japan

${ }^{2}$ Faculty of Health Science Toho University, Miyama 2-2-1, Funabashi, Chiba 274-8510, Japan

${ }^{3}$ Faculty of Nursing, Department of Nursing, Tokyo Ariake University of Medical and Health Sciences 2-9-1 Ariake, Koto-ku, Tokyo 135-0063, Japan

\section{Abstract}

Background: Most first parents experience childbirth with little preparation for child-rearing after birth. However, after childbirth, parents often have a hard time coping with night-time feeding or baby's crying. This study seeks to evaluate the effects of an intervention class providing parenting support during pregnancy. The program focuses on mother-infant interaction.

Methods: Participants were primipara pregnant women attending a birth center. The intervention class was offered as an addition to maternity classes. The intervention addressed fetal development, mother-newborn interaction, baby's sleeping and waking states, baby's self-regulation, and infant cues. The intervention group answered questionnaires containing a Prenatal Attachment Inventory (PAI) and Nurturance scales before and after the additional class; the control group answered questionnaires in the third or fourth regular maternity class. Mothers in both groups were also asked to complete a postnatal questionnaire, Maternal Attachment Inventory (MAI), and Edinburgh Postnatal Depression Scale (EPDS).

Results: The intervention group included 12 primiparas (initially 13), and the control group included 12 primiparas. There was no difference in baseline (Time 1) data between the intervention group and control group, nor differences in MAI and EPDS scores postnatally (Time 3). However, the PAI score increased significantly after the intervention class (Time 2) in the intervention group. The Nurturance subordinate scale "Acceptance" also increased for the intervention group between Time 1 and Time 2.

Conclusion: The early intervention parenting support class considered herein enhances attachment to the baby and acceptance in the short term, but there is no long-term effect. The implementation of multiple interventions and exploration of long-term effects are future challenges.

\section{Introduction}

Maternal support during pregnancy often focuses solely on preparation for childbirth. Therefore, most first parents experience childbirth with little preparation for child-rearing after birth. However, after childbirth, parents often have a hard time coping with night-time feeding or baby's crying; mothers feel more stress and difficulty than expected. Parent-baby relationships affect later child development, especially social-emotional development and cognitive development [1]. Recognizing infant signs and how to respond to them creates successful mother-infant interactions that bring advantage to both mother and infant.

Research indicates many positive effects of intervention both before and after delivery. Antenatal and postnatal intervention promotes the Mother-infant relationship and prevents postnatal depression [2]. Systematic review of parenting interventions shows effectiveness of improving the relationship between mothers and their preterm infants [3].

Attachment intervention and teaching mothers about state modulation are quite effective [4-6], as is intervention to promote mother-infant interaction and teach mothers state modulation in preterm infants [7-10]. Kusanagi's intervention takes place in the hospital in the Neonatal Intensive Care Unit before discharge; Kang's intervention is both in hospital and at home after discharge; and other interventions are after discharge and home visits. However, as most researchers start intervention after delivery, there is little prenatal couple intervention research on enhancing parent-child interaction $[11,12]$.

The aim of this study is to investigate intervention focused on the mother-infant relationship earlier, during pregnancy, rather than during child-rearing, and to evaluate outcomes of parenting support during pregnancy, before and after intervention, and postnatally.

\section{Methods \\ Participants}

The participants, both intervention group and control group, were primipara pregnant women attending a birth center. Intervention group primiparas attended a maternity class held in the birth center from one to four times, and agreed to attend one extra session of class. The control group were primiparas who attended (or planned to attend) the usual four sessions held by the birth center. To avoid information exchange and prevent any feelings of unequal support between intervention and control groups, intervention and nonintervention periods were alternated: intervention group members were recruited from the June-July, November-December, and

"Corresponding Author: Dr. Mami Sonobe, Department of Nursing Sciences, Graduate School of Human Health Sciences, Tokyo Metropolitan University, 7-210 Higashiogu, Arakawa-ku, Tokyo 116-8551, Japan; E-mail: sonobe@tmu.ac.jp

Citation: Sonobe M, Usui M, Hirose T (2018) Early Intervention to Support Parenting during Pregnancy: Improving Parent-Child Interactions. Int J Nurs Clin Pract 5: 296. doi: https://doi.org/10.15344/2394-4978/2018/296

Copyright: (C) 2018 Sonobe et al. This is an open-access article distributed under the terms of the Creative Commons Attribution License, which permits unrestricted use, distribution, and reproduction in any medium, provided the original author and source are credited. 
February-March sessions; control group members were recruited from the April-May and September-October sessions. Control group members received no information about additional classes and were only asked to answer questionnaires.

\section{Procedure}

An early intervention parenting support class was offered as an additional class session to maternity classes scheduled to meet for four sessions. A total of 13 primipara pregnant women participated in the extra session during 3 administrations of the maternity class's extra session sequence. The intervention group answered questionnaires containing the same contents before and after the additional class and an evaluation form. The purpose of the research was explained to the control group, and members were asked to answer the questionnaire in the third or fourth regular maternity class. Mothers in both groups were also asked to complete a postnatal questionnaire during the one-month check-up at the birth center, and to mail it back to the researcher.

\section{Intervention class programs}

The two instructors for the additional class were qualified and licensed midwives, trained and licensed in NCAST (Nursing Child Assessment Satellite Training), which provides a mother-infant interaction assessment tool. The additional maternity class took ninety minutes. The class used a small-group, participatory style. The intervention class program was composed of six elements.

1. Self-introduction: Name, gestational age, any information that participants want to share to understand each other reciprocally.

2. Fetal development: Fetus uses sensory organs, becomes light sensitive, listens to outside world sounds, feels comfortable in the amniotic fluid, sucks fingers, and urinates. Fetuses are able to hear music, mother's and father's voices. Participants discussed their experience of fetal movement or response to talking and hearing sounds.

3. Mother-newborn interaction shortly after birth: We showed a part of the DVD Mother's Enjoyable Communication with Her Baby [13] to the participants: A few hours after birth the baby appears to respond to mother's talking, turns her/his head toward mother, and vocalizes to the mother. The baby reacts to an old children's song sung to the baby during pregnancy. The baby enjoys conversation.

4. Baby's sleeping and waking states: We demonstrated the 6 states $[14,15]$, characteristics of sleeping and waking states, activities caregivers can carry out in each state, and demonstrated which state is most suitable for feeding or interacting.

5. Baby's self-regulation: We made and used a booklet to teach statemodulation techniques $[14,16]$. We taught a variety of methods to awaken sleepy babies, how a baby soothes herself/himself, and how mothers can help their babies and how to understand the newborn's ability to develop self-regulating behaviors, for example, sucking behaviors and self-soothing strategies.

6. Infant cues: We taught infant engagement/disengagement cues by showing pictures of infant cues based on the NCAST teaching materials, Baby Cues[17]. And we showed and discussed babies' communication cues and verbal and non-verbal behaviors that communicate wants and needs.

\section{Measures \\ Prenatal/Maternal Attachment}

The prenatal attachment inventory (PAI) was developed by Muller [18]; the Japanese version (PAI-J) was revised and standardized for Japanese samples by Ohmura. This scale has 21 items, rated on a four-point Likert scale, and has proven reliability and validity. The reliability coefficient of the PAI-J is Cronbach's $\alpha=0.89$. Higher scores indicate higher attachment to the fetus.

The maternal attachment inventory (MAI) was also developed by Muller [19], and the Japanese version (MAI-J) was revised and standardized for Japanese samples by Ohmura. This scale has 26 items, rated on a four-point Likert scale, and has proven reliability and validity [20]. The reliability coefficient of the MAI-J is Cronbach's $\alpha=0.932$. This scale was used after birth. Higher scores indicate higher attachment to the baby.

\section{Nurturance}

Nurturance was conceptualized by Fogel, Melson [21]; cooperative researcher Kojima disseminated the concept in Japan [22]. Nurturance is fostering someone; it is a quality possessed by all people, from children to adults, and includes a life-span developmental aspect. The nurturance scale was developed by Kurumisawa [23] and has 25 items, comprising four subscales: empathy, skill, preparedness, nonacceptance. Each subscale total is analyzed independently.

\section{Postnatal depressive symptoms}

Postnatal depressive symptoms were measured using the Edinburgh Postnatal Depression Scale (EPDS) [24,25]. The EPDS is a screening test for postnatal depression developed in the UK. It is widely used, and comprises 10 items based on a Likert Scale from 0-3, higher scores indicating more depressive. The Japanese EPDS has been confirmed as a valid and reliable screening tool [26]. The cut-off point in Japan is 9; over 9 is considered to be a high score.

\section{Ethical considerations}

This study was approved by the Tokyo Metropolitan University Faculty of Health Sciences safety ethics committee. Participants were informed by explanation and document about the following points: aim and outline of the study; voluntary participation and/or withdrawal; protection of their privacy; handling and disposal of data; and that refusal was irrelevant to medical treatment and midwifery care. Informed consent was then obtained.

\section{Results}

Figure 1 presents the timing of measurements. In the intervention group, one participant during pregnancy was excluded after the intervention class because obstetric abnormality made her unavailable for post-delivery questionnaires. Finally, a total of 12 subjects remained in each group.

\section{Characteristics of participants}

Table 1 shows characteristics of participants. Gestational age at Time 1 was earlier in the intervention group than in the control group. "Experience of taking care of a child" meant caring for a younger sibling or other relative, a friend's children, and/or working as a childcare worker. 


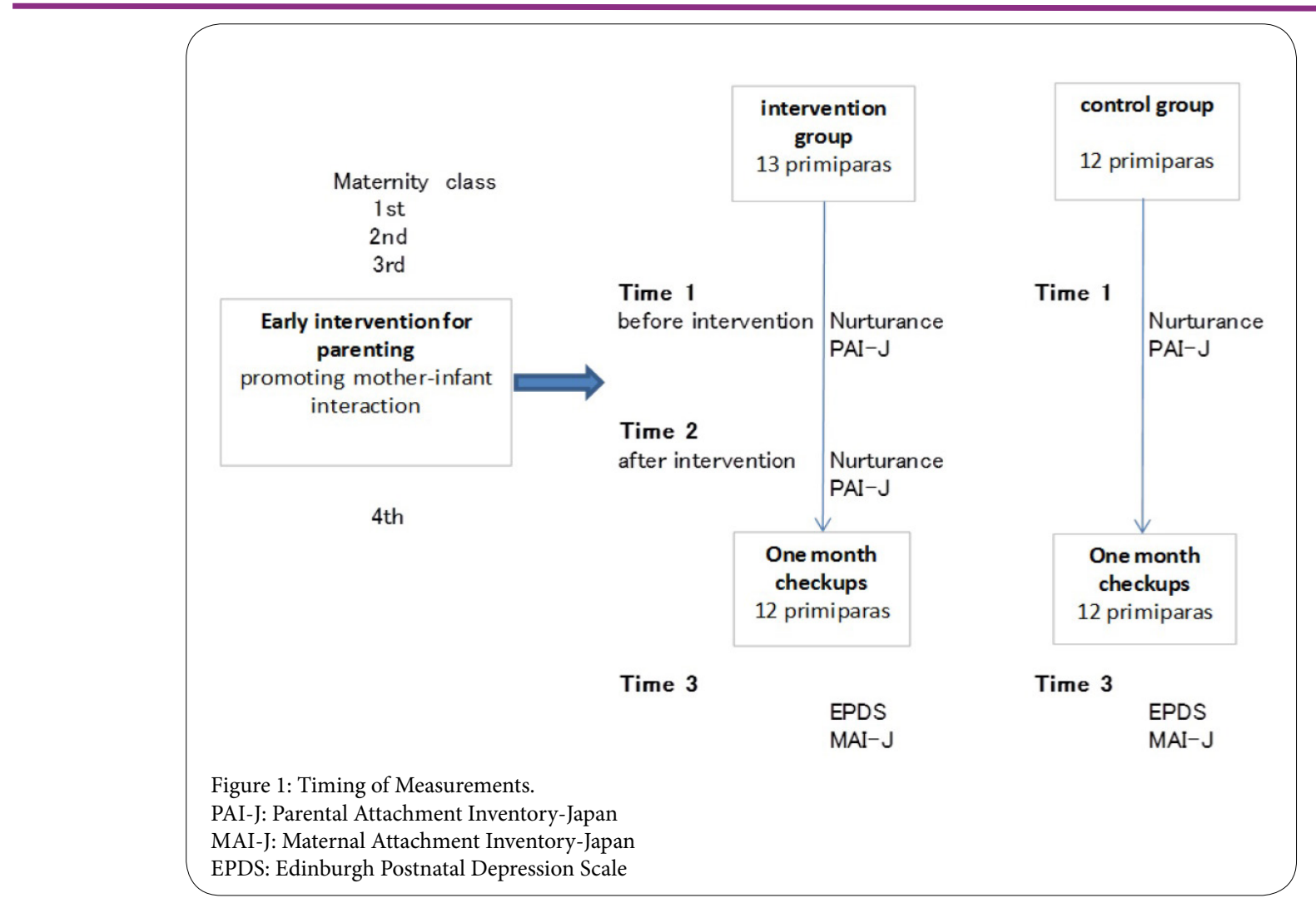

\begin{tabular}{|l|c|c|}
\hline & Intervention (N=13) & Control (N=12) \\
\hline Age in years Mean (SD) & $31.9(4.3)$ & $31.8(4.7)$ \\
$\begin{array}{l}\text { Gestational age in weeks at } \\
\text { research start Mean (SD) }\end{array}$ & $22.9(6.4)$ & $33.3(4.1)$ \\
$\begin{array}{l}\text { Experience of taking care of } \\
\text { a child (\%) }\end{array}$ & $6(46.2)$ & $8(66.7)$ \\
\hline \multicolumn{2}{l}{ Table 1: Characteristics of participants. } \\
\hline
\end{tabular}

\section{Evaluation of intervention class}

Nine participants in the intervention class answered "very satisfied", three "satisfied", one "a little satisfied" with the class. Regarding ease of understanding, eleven reported "very easy to understand", and two "almost easy to understand".

\section{Pregnancy and delivery data}

Table 2 shows pregnancy and delivery data. In the type of delivery, one participant in the intervention group had Caesarean section delivery in the hospital. The participant reporting 'Not satisfied' during pregnancy in the control group said she regretted the heightened concentration on exercise and quality of life. The woman in the control group who answered 'Not satisfied' with childbirth was taken from the birth center to the hospital during delivery but had vaginal delivery.

\section{Changes before and after intervention}

Table 3 presents changes before and after intervention. The PAI-J score at Time 2 was significantly increased from Time $1(\mathrm{P}=0.041)$ On the other hand, the Nurturance subscale item 'non-acceptance' significantly decreased from Time 1 to Time $2(\mathrm{P}=0.001)$.

\section{Attachment, Nurturance, and EPDS in both groups}

Table 4 presents PAI-J, MAI-J, Attachment, Nurturance, and EPDS scores at Time 1 and Time 3 in both groups. In both groups the Nurturance subscales and EPDS showed no significant differences.

\section{Discussion}

There is no difference in Timel baseline data between the intervention group and control group, nor differences in MAI and EPDS scores at Time 3 . However, the PAI score increased significantly between baseline (Time 1) and intervention class (Time 2) in the intervention group. Acceptance also increased for the intervention group between Time 1 and Time 2 .

The mother interacts with the fetus and creates a relationship during pregnancy [27]. This prenatal attachment is promoted by feeling fetal movement and gestational growth [28], and by watching images of the fetus through obstetric ultrasonography $[29,30]$. The development of a successful mother-child relationship is assumed to influence the later parent-child relationship and particularly benefits children [28]. Although the increased prenatal attachment before and after the intervention class was a short-term effect, transient rising scores could indicate effectiveness of intervention and be used to assess intervention. PAI scores during pregnancy correlate to MAI scores after delivery [31,32], and prenatal attachment predicts mother-child relationships in the postnatal period. How much prenatal attachment can be promoted during pregnancy could be significant.

Of the four nurturance subscales, acceptance increased, indicating skill and attitude toward raising children improved. Usually as pregnancy progresses primiparas' nurturance score decrease. This is accounted for by anxiety about childbirth and child rearing, lowering 
Citation: Sonobe M, Usui M, Hirose T (2018) Early Intervention to Support Parenting during Pregnancy: Improving Parent-Child Interactions. Int J Nurs Clin Pract 5: 296. doi: https://doi.org/10.15344/2394-4978/2018/296

\begin{tabular}{|lcc|}
\hline & Intervention $(\mathrm{N}=12)$ & Control $(\mathrm{N}=12)$ \\
\hline Type of delivery (\%) & & $12(100)$ \\
Vaginal delivery & $11(92.7)$ & $0(0.0)$ \\
Caesarean section & $1(7.3)$ & $39.1(0.9)$ \\
Gestational age in weeks at delivery Mean (SD) & $39.1(1.2)$ & $4(33.3)$ \\
\hline Satisfaction during pregnancy (\%) & & $7(58.3)$ \\
Fully satisfied & $7(58.3)$ & $1(8.4)$ \\
Satisfied & $5(41.7)$ & $9(75.0)$ \\
Not satisfied & $0(0.0)$ & $2(16.7)$ \\
\hline Childbirth satisfaction (\%) & $10(83.3)$ & $1(8.3)$ \\
Fully satisfied & $2(16.7)$ & \\
Satisfied & $0(0.0)$ & \\
Not satisfied & & \\
\hline Table 2: Pregnancy and delivery data. & & \\
\hline
\end{tabular}

\begin{tabular}{|lllcccc|}
\hline & \multicolumn{2}{c}{ Time 1 } & \multicolumn{3}{c|}{ Time 2 } \\
& & Mean & SD & Mean & SD & P-value \\
\hline \multirow{3}{*}{ Nurturance } & PAI-J & 62.2 & 10.4 & 65.7 & 9.7 & $0.041^{*}$ \\
& empathy & 46.0 & 5.5 & 46.9 & 6.0 & 0.323 \\
& skill & 22.3 & 6.3 & 23.2 & 6.1 & 0.472 \\
& preparedness & 17.6 & 2.2 & 16.8 & 3.0 & 0.136 \\
& non-acceptance & 12.5 & 2.8 & 10.8 & 2.9 & $0.001^{*}$ \\
\hline
\end{tabular}

Table 3: Changes before and after intervention $(\mathrm{N}=13)$.

SD: standard deviation; Wilcoxon signed rank test; ${ }^{*} \mathrm{P}<0.05$

PAI-J: Parental Attachment Inventory-Japan

\begin{tabular}{|c|c|c|c|c|c|c|c|c|c|}
\hline & & \multicolumn{4}{|c|}{ Time 1} & \multicolumn{4}{|c|}{ Time 3} \\
\hline & & $\mathrm{N}$ & Mean & $\mathrm{SD}$ & P-value & $\mathrm{N}$ & Mean & SD & $\mathrm{P}$-value \\
\hline \multirow[t]{2}{*}{ PAI-J (Time 1), MAI-J (Time 3) } & Intervention & 13 & 62.2 & 10.4 & 0.892 & 12 & 85.4 & 26.8 & 0.148 \\
\hline & Control & 12 & 61.8 & 11.7 & & 12 & 95.6 & 7.9 & \\
\hline Nurturance & Intervention & 13 & 46.0 & 5.5 & 0.298 & - & - & - & - \\
\hline & Control & 12 & 43.2 & 6.4 & & - & - & - & - \\
\hline skill & Intervention & 13 & 22.3 & 6.3 & 0.806 & - & - & - & - \\
\hline & Control & 12 & 22.7 & 6.9 & & - & - & - & - \\
\hline preparedness & Intervention & 13 & 17.6 & 2.2 & 0.761 & - & - & - & - \\
\hline & Control & 12 & 17.8 & 2.3 & & - & - & - & - \\
\hline non-acceptance & Intervention & 13 & 12.5 & 2.8 & 0.476 & - & - & - & - \\
\hline & Control & 12 & 14.4 & 4.9 & & - & - & - & - \\
\hline \multirow[t]{2}{*}{ EPDS } & Intervention & 12 & & & & & 7.9 & 4.2 & 0.162 \\
\hline & Control & 12 & & & & & 5.8 & 4.3 & \\
\hline
\end{tabular}

Table 4: Attachment, Nurturance, and EPDS in both groups.

SD: standard deviation; Mann-Whitney's U test

PAI-J: Parental Attachment Inventory-Japan

MAI-J: Maternal Attachment Inventory-Japan

EPDS: Edinburgh Postnatal Depression Scale

primiparas' confidence about raising children. Like nurturance preventing this decrease in confidence leads to positive child rearing after birth. Therefore, increasing nurturance by intervention classes is effective.

However, maternal attachment and postnatal depression scales at one month after birth show no difference in either group, so there is no long-term effect. Increasing frequency of measurements of prenatal attachment and nurturance during pregnancy, implementation of multiple interventions and exploration of long-term effects are future challenges.

\section{Conclusion}

To carry out this study, we conducted an intervention class focused on the mother-infant interaction during pregnancy, and evaluated a number of factors influencing maternal attachment before and after intervention, and postnatally. The findings were as follows. There were no differences in baseline (Time1) data between intervention group and control group, no differences in MAI and EPDS scores postnatally (Time 3 ). However, the PAI score increased significantly in the intervention group after the intervention class (Time 2), and acceptance also increased for the intervention group between Time 1 
Citation: Sonobe M, Usui M, Hirose T (2018) Early Intervention to Support Parenting during Pregnancy: Improving Parent-Child Interactions. Int J Nurs Clin Pract 5: 296. doi: https://doi.org/10.15344/2394-4978/2018/296

Page 5 of 5

and Time 2. Results suggest the early intervention parenting support class enhances attachment to the baby and acceptance in the short term, but there is no long-term effect.

\section{Acknowledgments}

The authors acknowledge the participating mothers and the birth center director. The authors also would like to thank Thane Doss whose suggestions and proofreading made an enormous contribution to this study

\section{Funding}

This study was supported by JSPS KAKENHI Grant Number 25463488 .

\section{Author Contributions}

M. S. generalized this study, performed research design, contributed to recruitment of subjects, carrying out intervention, acquisition of data, analysis, manuscript composition. M. U. contributed to recruitment of subjects, the carrying out intervention, acquisition of data. T. H. advised on creation of materials and conduct of intervention class.

\section{Competing Interests}

The authors declare that they have no competing interests.

\section{References}

1. Sumner G, Spietz A (2004) Caregiver/Parent-Child Interaction Teaching Manual, Seattle, WA: NCAST Publications. USA.

2. Cooper PJ, De Pascalis L, Woolgar M, Romaniuk H, Murray L, et al. (2015) Attempting to prevent postnatal depression by targeting the mother-infant relationship: A randomised controlled trial. Prim Health Care Res Dev 16 383-397. DOI: $10.1017 / \mathrm{s} 1463423614000401$

3. Evans T, Whittingham K, Sanders M, Colditz P, Boyd RN, et al. (2014) Are parenting interventions effective in improving the relationship between mothers and their preterm infants? Infant Behav Dev 37: 131-154. DOI: 10.1016/j.infbeh.2013.12.009

4. Carmen S (1994) Attachment intervention. InfYoung Children7: 8.

5. Komoto K, Hirose T, Omori T, Takeo N, Okamitsu M, et al. (2015) Effect of early intervention to promote mother - infant interaction and materna sensitivity in Japan: A parenting support program based on infant mental health. J Med Dent Sci 62: 77-89. DOI: 10.11480/jmds.620401

6. Page PA (1992) An investigation of the relationship between maternalinfant patterns of synchrony during feeding, preterm infant state and a parent-administered state modulation treatment. University of Washington.

7. Cho Y, Hirose T, Tomita N, Shirakawa S, Murase K, et al. (2013) Infant menta health intervention for preterm infants in Japan: Promotions of maternal mental health, mother-infant interactions, and social support by providing continuous home visits until the corrected infant ege of 12 months. Infant Mental Health J 34: 47-59. DOI: 10.1002/imhj.21352

8. Kang R, Barnard K, Hammond M, Oshio S, Spencer C, et al. (1995) Preterm infant follow-up project: a multi-site field experiment of hospital and home intervention programs for mothers and preterm infants. Public Health Nurs 12: $171-180$

9. Kusanagi M, Hirose T, Mikuni K, Okamitsu M (2011) Effect of early intervention using state modulation and cue reading on mother-infant interactions in preterm infants and their mothers in Japan. J Med Dent Sc 58:89-96.

10. Ravn IH, Smith L, Smeby NA, Kynoe NM, Sandvik L, et al. (2012) Effects of early mother-infant intervention on outcomes in mothers and moderately and late preterm infants at age 1 year: A randomized controlled trial. Infant Behav Dev 35: 36-47.
11. Bryan AA (2000) Enhancing parent-child interaction with a prenatal couple intervention. MCN Am J Matern Child Nurs 25: 139-145.

12. Horiguchi M (2005) Parenting education during prenatal period: A program with gender and developmental perspectives in the US. F-GENS Journal 4: 13-20.

13. Japanese Midwives Association (2007) Mother's Enjoyable Communication with Her Baby [DVD], Tokyo, Japan.

14. Barnard KE (1999) Beginning Rhythms: The Emerging Process of Sleep Wake Behavior and Self-Regulation. Seattle, Washington: NCAST Publications.

15. Brazelton TB, Nugent JK (2011) Neonatal Behavioral Assessment Scale. London: Mac Keith Press.

16. Bronson MB (2000) Self-Regulation in Early Childhood. New York: Guilford.

17. Programs N (2003) Baby Cues: A Child's First Language. Seattle, WA: Ncast Programs, University of Washington.

18. Muller ME (1993) Development of the Prenatal Attachment Inventory. West Jure Res 15: 199-211.

19. Muller ME (1994) A questionnaire to measure mother-to-infant attachment. J Nurs Meas2:129-141.

20. Ohmura N, Yamatogi $Y$, Matsubara M (2001) Mother's internal working models and perinatal attachment. J Jpn Acad Nurs Sci 21:71-79.

21. Fogel A, Melson GF (1986) Origins of Nurturance: Developmental, Biological and Cultural Perspectives on Caregiving. London: Lawrence Erlbaum Associates.

22. Kojima H (1989) Social World of the Infant. Tokyo: Yuhikaku.

23. Kurumisawa R (2012) Nurturance Development and Formation Factors in Adolescence and Adulthood. Tokyo: Kazama syobou.

24. Cox J, Holden J (1994) Perinatal Psychiatry: Use and Misuse of the Edinburgh Postnatal Depression Scale. London: Gaskell.

25. Cox JL, Holden JM, Sagovsky R (1987) Detection of postnatal depression. Development of the 10-item Edinburgh Postnatal Depression Scale. Br J Psychiatrisrs 150: 782-786.

26. Okano T, Murata M, Masuji F (1996) Validation and reliability of Japanese version of EPDS (Edinburgh Postnatal Depression Scale). Archives of psychiatric diagnostics and clinical evaluation 7: 525-533.

27. Brandon AR, Pitts S (2009) Denton WH, Stringer CA, Evans HM. A history of the thory of prenatal attachment. J Prenat Perinat Psychol Health 23: 201-222.

28. Muller ME (1992) A critical review of prenatal attachment research. Sch Inq Nurs Pract 6: 5-22.

29. Pretorius DH, Gattu S, Ji EK, Hollenbach K, Newton R, et al. (2006) Preexamination and postexamination assessment of parental-fetal bonding in patients undergoing 3-/4-dimensional obstetric ultrasonography. J Ultrasound Med 25: 1411-1421.

30. Lumley J (1990) Through a glass darkly: Ultrasound and prenatal bonding Birth 17: 214-217.

31. Muller ME (1996) Prenatal and postnatal attachment: A modest correlation J Obstet Gynecol Neonatal Nurs 25: 161-166.

32. Siddiqui A Eisemann M, Hagglof B (2000) The stability of maternal interpretation of infant's facial expressions during pre-and postnatal period and its relation to prenatal attachment. Early Child Dev Care 162: 41-50. 